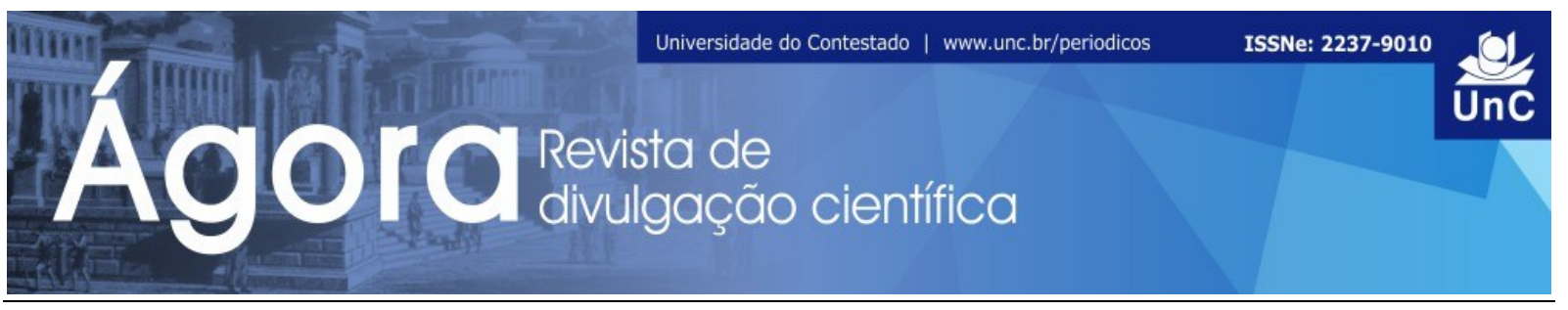

\title{
VANTAGENS DOS FUNDOS IMOBILIÁRIOS COMO FORMA DE APLICAÇÃO NO MERCADO IMOBILIÁRIO PARA O PEQUENO INVESTIDOR
}

Guilherme Cardoso Jesus ${ }^{1}$

RESUMO: Os antepassados sempre diziam que investir em imóveis era um investimento com um retorno excelente e seguro, mas sabe-se que nem todos têm condições de investir devido ao alto custo que acaba se tornando. Com isso foi criado os Fundos Imobiliários que aproximaram o pequeno investidor da possibilidade de diversificar seu portfólio de investimentos no mercado imobiliário. Neste caso o objetivo do estudo é compreender o que é o Fundo Imobiliário e apresentar ao pequeno investidor uma porta de acesso para aplicações no mercado imobiliário através das Flls e com isso trazer diversificação para sua carteira de investimentos. Também demonstrar a rentabilidade de um determinado Fundo Imobiliário por um certo período e fazer uma comparação com a poupança, uma das mais antigas e populares formas de aplicação financeira existente no Brasil. Alguns autores como Martini explicam a importância dos Fll's e os riscos e vantagens desta ferramenta de investimento. $\mathrm{O}$ artigo tem seu procedimento metodológico disciplinar com sua pesquisa pura, o autor busca aplicar uma pesquisa histórica, seu objetivo descritivo e tendo como meio de investigação utilizará a pesquisa bibliográfica e análise de dados.

Palavras-Chaves: Fundo Imobiliário. Investimentos. Diversificação. Rentabilidade.

\section{ADVANTAGES OF REAL ESTATE FUNDS AS A FORM OF APPLICATION IN THE REAL ESTATE MARKET FOR SMALL INVESTORS}

ABSTRACT: The ancestors always said that investing in real estate was an investment with an excellent and safe return, but it is known that not everyone can invest due to the high cost that ends up becoming. With this was created Real Estate Funds that bring the small investor closer to being able to diversify their portfolio of investments in the real estate market. In this case, the purpose of the study is that of the Investment Fund and presents a short survey of the access door for non-real estate applications through the IFIs and their investment portfolio. Also demonstrate a profitability of a particular Real Estate Fund for a certain period and make a compensation with a savings, one of the oldest and most popular forms of financial application in Brazil. Some authors like Martini explain the importance of the risks of

\footnotetext{
${ }^{1}$ Graduado em Administração. UNESC Universidade do Extremo Sul Catarinense. Especialista MBA em Gestão Estratégica de Finanças e Controladoria. UNESC. Universidade do Extremo Sul Catarinense. Criciúma. Santa Catarina. Brasil. E-mail: guilhermecdi@gmail.com
}

Ágora: R. Divulg. Cient., v. 22, n. 1, p. 104-115, jan./jul. 2017 (ISSNe 2237-9010) 
the FII and the risks of this investment tool. The article has its methodological disciplinary procedure with its pure research, the author seeks to apply a historical research, its descriptive purpose and having as a means of investigation used a bibliographical research and data analysis.

Key-words: Real Estate Fund. Investments. Diversification. Profitability. Real estate.

\section{INTRODUÇÃO}

Sabe-se que um dos melhores investimentos que se tem falado até hoje são os investimentos em imóveis, por meio da aquisição de terrenos, casas ou apartamentos e que acabam gerando uma remuneração mensal através de alugueis e até mesmo a valorização do bem que o mesmo possibilita. Os antepassados sempre diziam que "quem compra terra não erra", mas nem todos têm acesso a esta modalidade de investimento, devido à grande quantidade de dinheiro que é necessário inicialmente ser disponibilizado no momento da compra.

Segundo Valim (2013), o investimento em imóveis requer certo cuidado. Muitas vezes, ao comprar um imóvel, o comprador tem que se certificar que o local possui tendência de expansão, se a localização é segura, se possui todas as infraestruturas adequadas para o crescimento do bairro e se o imóvel possui toda documentação, além de outras considerações.

Vale ressaltar que o investimento em imóveis sempre foi um dos mais seguros e rentáveis quando se trata da relação entre risco e retorno, porém ainda está longe de ser o melhor investimento no Brasil, pois ele deixa a desejar quando se fala em liquidez. Na necessidade de converter o bem em dinheiro, chama-se isso de liquidez, o proprietário do imóvel não consegue de imediato realizar a venda, comprometendo muitas vezes, a situação financeira do investidor e até mesmo do retorno do investimento, visto que o mesmo teria que se desfazer por um valor abaixo do que estaria sujeito a vender inicialmente.

Conforme Scolese (2015), os investimentos em imóveis podem ser de caráter de consumo ou de investimentos. A pessoa pode ter simplesmente o sonho da casa própria e com isso encarar o Crédito Imobiliário para realizar o tão sonhado desejo de consumo ou comprá-lo à vista, ou o investidor individual pode realmente adquirir 
o imóvel com o intuito de colocá-lo para alugar ou meses depois colocá-lo a venda, obtendo um ganho pela diferença entre o valor da compra e o valor da venda.

Como foi falado anteriormente, investir em imóveis nunca foi para qualquer um, somente pessoas com grande poder aquisitivo poderiam adquirir imóveis devido ao preço que se é praticado neste mercado. Deve-se chamar atenção ao fato de que o imóvel nem sempre pode ser tratado como ferramenta de investimento, porque dependendo de qual o intuito da compra do imóvel, o mesmo estaria sendo considerado como uma despesa, que é o caso de quem financia um imóvel com o objetivo de morar e não alugar. Neste momento, o imóvel não está ligado diretamente a ferramenta de investimento porque o proprietário não está tendo remuneração mensal, e sim, tendo que pagar muitas vezes uma parcela razoavelmente alta e o valor financiado acaba tirando a valorização que se teria com o bem.

Deste modo, o pequeno investidor sempre ficou atrelado a investimentos de qualidade duvidosa e não tinha a oportunidade de entrar no mercado imobiliário. Grande parcela da população brasileira, quando se trata de investimento, tem como referência a poupança, por ser a mais antiga e a mais popular forma de rentabilização mensal, e segura, com risco limitado para o dono do dinheiro, pois é coberta pelo FGC (Fundo Garantidor de Crédito).

Só que hoje em dia, o mercado de investimentos cresceu e com eles, melhores aplicações surgiram ao pequeno investidor. São muitas as opções de investimentos disponíveis no mercado financeiro, os bancos e as corretoras apresentam ótimas aplicações que requerem um valor inicial baixo. Até mesmo os imóveis, que eram impossíveis de serem adquiridos pelo investidor individual, hoje são opções disponíveis no mercado imobiliário a um preço bem menor. Este estudo, mais à frente irá aprofundar ainda mais o assunto sobre o mercado imobiliário.

De acordo com Scolese (2015), nos últimos anos houve uma crescente procura e, consequentemente, o interesse por investimentos no mercado imobiliário.

Nem sempre investir em imóveis depende apenas em ter o dinheiro para a compra do bem, mas também necessita conhecimentos sobre o mercado imobiliário e, muitas vezes, o investidor não detém este conhecimento, o que acaba afastando também do investimento. 
Desse modo, o objetivo do estudo é compreender o que é o Fundo Imobiliário e apresentar ao pequeno investidor uma porta de acesso para aplicações no mercado imobiliário através dos Fundos de Investimentos Imobiliários (FIls) e, com isso, trazer diversificação para sua carteira de investimentos. Também demonstrar a rentabilidade de um determinado Fundo Imobiliário por um certo período e fazer uma comparação com a poupança, uma das mais antigas e populares formas de aplicação financeira existente no Brasil.

\section{FUNDAMENTAÇÃO TEÓRICA}

\subsection{CADERNETA DE POUPANÇA}

Segundo Martini (2013), quando o investidor está direcionando seu capital para a renda fixa, neste caso pode-se considerar a caderneta de poupança como renda fixa. Ele está emprestando esta quantia ao emissor do título para, em troca, receber o mesmo valor que foi aplicado juntamente com os juros que foram acordados entre tomador e investidor.

A poupança é considera hoje uma das formas de investimento mais popular no Brasil, segundo informações do Banco Central, 98\% das pessoas que possuem saldo aplicado tem menos de $\mathrm{R} \$ 50$ mil em conta. Uma das características dela é ser conservadora, não há risco para o investidor e também não possui imposto de renda para pessoa física (CANALINI, 2012).

Como caracteriza Martini (2013), a caderneta de poupança é o investimento mais seguro considerado pelo sistema financeiro, no qual também é conhecido por ser umas das aplicações com menor rendimento no mercado brasileiro, justamente pela segurança que o investimento apresenta e liquidez imediata.

De acordo com Banco Central do Brasil (2016), segundo a legislação atual, existem duas parcelas na remuneração da poupança, composta pela remuneração básica, dada pela taxa referencial (TR) e 0,5\% como remuneração adicional enquanto a taxa Selic estiver superior a $8,5 \%$ ao ano. Quando a taxa Selic estiver inferior a $8,5 \%$ ao ano, será remunerado $70 \%$ da meta da taxa Selic ao ano juntamente com a taxa referencial. 
Um dos índices que remuneram a caderneta de poupança é a Taxa Referencial (TR), muitas pessoas confundem com o indexador da inflação, mas não é. A Taxa Referencial é uma parcela de juros pós-fixado que dependem do nível das taxas de juros praticadas pelas 30 maiores instituições financeiras em termo de captação de deposito a prazo, ou seja, os certificados de depósitos Bancários (CDB) e Recibos de Depósitos Bancários (RDB). Somando a TR com o 0,5\% a.m. teremos então a remuneração da caderneta de poupança. (VEIGA, 2009)

Conforme o Banco Central do Brasil (2016), os rendimentos são creditados na conta do investidor nas datas de aniversários que correspondem a data em que foi depositado o valor, então 30 dias corridos após esta data é feito o crédito. No caso de cliente pessoa jurídica, o crédito ocorre 90 dias após a data de aniversário.

A caderneta de poupança possui algumas regras básicas que devem ser tomadas pelo aplicador para não ser penalizado, dentre elas, o valor deve ficar em conta por um prazo mínimo de 30 dias corridos após a data de aniversário, para que pequeno investidor possa receber seu rendimento referente ao valor depositado em sua conta. (CANALINI, 2012)

Os dados obtidos através do site do Banco Central (2016), mostram a quantidade em valores sobre o montante aplicado na caderneta de poupança no período de novembro de 2016 que é de $\mathrm{R} \$ 647.730 .698,00$.

\subsection{RENDA VARIÁVEL}

Uma das importâncias fundamentais antes de investir é conhecer os conceitos entre renda variável e renda fixa, pois a partir daí será possível saber como será a forma de calcular seus investimentos, um fator importantíssimo na hora de realizar um planejamento financeiro. (MARTINI, 2013)

Segundo Dallagnese (2007), os ativos em renda variável são conhecidos por apresentar grande volatilidade em seus índices que remuneram sua carteira de investimento, sejam elas em ações, dólar, ouro e por apresentarem grande risco no curto prazo, mas que também de longo prazo frequentemente apresentam rentabilidades bastante atrativas.

Conforme Martini (2013), diferente dos investimentos de renda fixa, onde no momento da aplicação o investidor já sabe o quanto terá ao final do prazo aplicado, 
a renda variável não dá essa informação, o valor da sua aplicação pode variar conforme as taxas do mercado.

A renda variável é recomendada a investidores com perfil moderado a arrojado, justamente por apresentarem grandes riscos ao seu capital investido e por não definir qual será sua remuneração ao final do prazo estabelecido. Os seus valores quem define é o próprio mercado onde um dos fatores é a oferta e demanda (COELHO, 2012).

Os ativos que compõem a renda variável são todos aqueles cujas rentabilidades não são possíveis de dimensionar, ou seja, não é possível que o investidor saiba no momento da aplicação quanto ele receberá ao final do vencimento (BRASIL. RECEITA FEDERAL, 2017).

\subsection{FUNDO IMOBILIÁRIO}

Um fundo de investimento seja ele imobiliário ou não, é uma aplicação em um regime de condomínio, pois assim como em um condomínio residencial que possuem condôminos, os fundos possuem cotistas que buscam em conjunto uma forma de rentabilizar ainda mais seus investimentos (CANALINI, 2012).

A instrução da CVM n. 472, de 31 de outubro de 2008 diz que todo fundo de investimento será constituído por deliberação de um administrador que preencha os requisitos estabelecidos. As cotas do fundo correspondem a frações ideais de seu patrimônio e devem ser escriturais e nominativas. Cotas dos fundos somente podem ser negociadas em mercados regulamentados, quando distribuídas publicamente por meio de oferta registrada na CVM, quando distribuídas com esforços restritos, observadas a restrição da norma especifica ou quando cotas da mesma serie já estejam admitidas a negociação em mercados regulamentados.

Com pouco recurso o investidor não consegue diversificar seus investimentos por dois motivos claros, um pelo baixo capital inicial que o investidor possui (baixo volume) e outro pela dificuldade de acesso ao mercado que exige uma quantia razoável para aplicação (CANALINI, 2012).

Segundo Carvalho (2012), o plano real de 1994 trouxe estabilidade a economia brasileira através do controle a inflação, trazendo ao cenário econômico brasileiro mais investidores o que resultou em uma infinidade de fundos de 
investimentos. Dado a tudo isso, surgiu os fundos de investimentos imobiliários com o intuito de investir em imóveis prontos ou empreendimentos imobiliários.

Segundo Scolese et al. (2015), as pessoas de caráter física têm como percepção de que os fundos imobiliários são seguros e apresentam baixa volatilidade em comparação a outros investimentos em renda variável, porém vale destacar que existem um componente de risco atrelado ao preço do papel e ao índice que compõe o rendimento dos aluguéis que fazem com que o fundo se enquadre a renda variável.

De acordo com BOVESPA (2016), O fundo de investimento imobiliário é um conjunto de recursos destinados a aplicação em ativos ligados diretamente ao mercado imobiliário. Cabe a um Administrador de uma determinada instituição financeira constituir o fundo e realizar todo o processo de captação de recurso.

Conforme Scolese et al. (2015), os fundos imobiliários possuem diferentes segmentos de atuação e são impactados por diferentes padrões de comportamentos, por este motivo se faz muito importante selecionar quais ativos irão compor o fundo.

De acordo com Bovespa (2016), os fundos são constituídos sob a forma de condomínio fechado, ou seja, não permite ao investidor realizar a venda antes do vencimento do fundo. Porém, pode ser negociado no mercado secundário, através do home broker.

O investimento em fundos imobiliários ainda se torna bastante viável devido ao grande avanço na economia e principalmente pelo crescimento que ocorre no setor imobiliário. $O$ investimento é de grande valia, porem se faz necessário ter cautela devido aos riscos inerentes (VALIM, 2013).

\section{PROCEDIMENTOS METODOLÓGICOS}

Em um primeiro momento o autor buscou outros autores que tratavam sobre assuntos relacionados a caderneta de poupança e aos fundos imobiliários. O próprio Scolese explica as diferentes modalidades dos fundos e o Banco Central o responsável pelas informações divulgadas referente a remuneração da caderneta de poupança. A pesquisa foi baseada nos históricos apresentados nos últimos 3 anos da remuneração da caderneta de poupança onde foi possível obter no próprio site 
do Banco Central e também a remuneração dos últimos 3 anos do Fundo Imobiliário que serviu de referência ao estudo onde foi buscado no site do gestor do fundo (FUNDO DE INVESTIMENTO MERITO). Através da pesquisa bibliográfica e na análise de dados o autor pode construir uma tabela onde deixa claro a remuneração anual de cada aplicação e com isso pode desenvolver uma simulação sobre um valor fictício para obtenção dos resultados esperados onde comparou as duas modalidades de investimentos.

\section{APRESENTAÇÃO E ANÁLISE DE DADOS}

O autor utilizou duas formas de investimentos, a poupança sendo ela bem conhecida pela população brasileira e pelo pequeno investidor, e a outra escolhida para o estudo é o fundo imobiliário, não tão conhecido pelo pequeno investidor, mas que pode ser uma nova modalidade de investimento que trará um retorno maior e que será comprovada durante a análise dos dados.

Todas informações referentes às remunerações de cada investimento foram retiradas do site do Banco Central e da Méritos Investimentos, esta última sendo a gestora do fundo que serviu de parâmetro de comparação para a pesquisa.

O fundo utilizado no estudo é o Mérito Desenvolvimento Imobiliário I FII que, no dia 05/04/17, tem como custo $\mathrm{R} \$ 104,00$ uma cota. O fundo tem por objetivo principal a aquisição de participações em empreendimentos de incorporações imobiliárias.

Após buscar informações relativas a caderneta de poupança, foi elaborada uma tabela na qual pode-se acompanhar a remuneração da caderneta de poupança dos anos compreendidos entre janeiro de 2014 e dezembro de 2016. Abaixo segue a tabela com as informações: 
Vantagens dos fundos imobiliários como forma de aplicação no mercado imobiliário para o pequeno investidor

Tabela 1 - Rentabilidade poupança entre 2014 e 2016

\section{POUPANÇA - 2014 / 2016 - Rentabilidade}

\begin{tabular}{c|c|c|c|c|c}
\hline jan/14 & $0,54 \%$ & $\mathrm{jan} / 15$ & $0,60 \%$ & $\mathrm{jan} / 16$ & $0,72 \%$ \\
\hline $\mathrm{fev} / 14$ & $0,61 \%$ & $\mathrm{fev} / 15$ & $0,58 \%$ & $\mathrm{fev} / 16$ & $0,63 \%$ \\
\hline $\mathrm{mar} / 14$ & $0,55 \%$ & $\mathrm{mar} / 15$ & $0,51 \%$ & $\mathrm{mar} / 16$ & $0,59 \%$ \\
\hline $\mathrm{abr} / 14$ & $0,52 \%$ & $\mathrm{abr} / 15$ & $0,63 \%$ & $\mathrm{abr} / 16$ & $0,71 \%$ \\
\hline $\mathrm{mai} / 14$ & $0,54 \%$ & $\mathrm{mai} / 15$ & $0,60 \%$ & $\mathrm{mai} / 16$ & $0,63 \%$ \\
\hline $\mathrm{jun} / 14$ & $0,56 \%$ & $\mathrm{jun} / 15$ & $0,61 \%$ & $\mathrm{jun} / 16$ & $0,65 \%$ \\
\hline $\mathrm{jul} / 14$ & $0,54 \%$ & $\mathrm{jul} / 15$ & $0,68 \%$ & $\mathrm{jul} / 16$ & $0,70 \%$ \\
\hline $\mathrm{ago} / 14$ & $0,60 \%$ & $\mathrm{ago} / 15$ & $0,73 \%$ & $\mathrm{ago} / 16$ & $0,66 \%$ \\
\hline $\mathrm{set} / 14$ & $0,56 \%$ & $\mathrm{set} / 15$ & $0,68 \%$ & $\mathrm{set} / 16$ & $0,75 \%$ \\
\hline out $/ 14$ & $0,58 \%$ & $\mathrm{out} / 15$ & $0,69 \%$ & $\mathrm{out} / 16$ & $0,65 \%$ \\
\hline nov $/ 14$ & $0,60 \%$ & $\mathrm{nov} / 15$ & $0,67 \%$ & $\mathrm{nov} / 16$ & $0,66 \%$ \\
\hline dez/14 & $0,54 \%$ & $\mathrm{dez} / 15$ & $0,63 \%$ & $\mathrm{dez} / 16$ & $0,64 \%$ \\
\hline Acumulado & $6,74 \%$ & Acumulado & $7,61 \%$ & Acumulado & $7,99 \%$ \\
\hline
\end{tabular}

Fonte: Pesquisa do Autor

O fundo Mérito desenvolvimento Imobiliário I FII teve as seguintes taxas de remuneração apresentadas entre os anos de janeiro de 2014 e dezembro de 2016. Quando se fala em fundos de investimentos deve-se lembrar que se trata de um grupo de pessoas (condôminos) que possuem os mesmos objetivos, alavancar seus investimentos buscando taxas de remuneração mais atrativas conforme Canalini (2012).

Tabela 2 - Rentabilidade do Fundo Imobiliário entre 2014 e 2016.

FUNDO IMOBILIÁRIO ( MERITO ) 2014 / 2016 Rentabilidade

\begin{tabular}{c|c|c|c|c|c}
\hline jan/14 & $1,00 \%$ & jan/15 & $1,10 \%$ & jan/16 & $1,12 \%$ \\
\hline $\mathrm{fev} / 14$ & $1,00 \%$ & $\mathrm{fev} / 15$ & $1,10 \%$ & $\mathrm{fev} / 16$ & $1,12 \%$ \\
\hline $\mathrm{mar} / 14$ & $1,00 \%$ & $\mathrm{mar} / 15$ & $1,10 \%$ & $\mathrm{mar} / 16$ & $1,12 \%$ \\
\hline $\mathrm{abr} / 14$ & $1,05 \%$ & $\mathrm{abr} / 15$ & $1,10 \%$ & $\mathrm{abr} / 16$ & $1,17 \%$ \\
\hline $\mathrm{mai} / 14$ & $1,05 \%$ & $\mathrm{mai} / 15$ & $1,12 \%$ & $\mathrm{mai} / 16$ & $1,17 \%$ \\
\hline $\mathrm{jun} / 14$ & $1,05 \%$ & $\mathrm{jun} / 15$ & $1,12 \%$ & $\mathrm{jun} / 16$ & $1,17 \%$ \\
\hline $\mathrm{jul} / 14$ & $1,05 \%$ & $\mathrm{jul} / 15$ & $1,12 \%$ & $\mathrm{jul} / 16$ & $1,17 \%$ \\
\hline $\mathrm{ago} / 14$ & $1,10 \%$ & $\mathrm{ago} / 15$ & $1,12 \%$ & $\mathrm{ago} / 16$ & $1,17 \%$ \\
\hline $\mathrm{set} / 14$ & $1,10 \%$ & $\mathrm{set} / 15$ & $1,12 \%$ & $\mathrm{set} / 16$ & $1,17 \%$ \\
\hline out $/ 14$ & $1,10 \%$ & $\mathrm{out} / 15$ & $1,12 \%$ & $\mathrm{out} / 16$ & $1,17 \%$ \\
\hline nov $/ 14$ & $1,10 \%$ & $\mathrm{nov} / 15$ & $1,12 \%$ & $\mathrm{nov} / 16$ & $1,17 \%$ \\
\hline dez/14 & $1,10 \%$ & dez $/ 15$ & $1,12 \%$ & $\mathrm{dez} / 16$ & $1,17 \%$ \\
\hline Acumulado & $12,70 \%$ & Acumulado & $13,36 \%$ & Acumulado & $13,89 \%$ \\
\hline
\end{tabular}

Fonte: Pesquisa do Autor

Após apresentar as tabelas acima, deixou-se claro para o autor que o fundo apresenta uma taxa de remuneração bem maior que a poupança. Mas a pergunta é: Qual a diferença em números que isso representa ao investidor? Com isso buscouse demonstrar através de um cálculo o quanto isso representa sobre um valor inicial aplicado.

Ágora: R. Divulg. Cient., v. 22, n. 1, p. 104-115, jan./jul. 2017 (ISSNe 2237-9010) 
Foram utilizados $R \$ 10$ mil reais como exemplo para cada ano em que o dinheiro ficaria aplicado, vale lembrar que no exemplo o investidor aplicou 10 mil durante 3 anos sem resgate algum, somente no final do período.

Tabela 3 - Poupança

\begin{tabular}{|c|c|c|c|c|}
\hline & \multirow{3}{*}{$\begin{array}{c}\text { IR } \\
\text { NDA }\end{array}$} \\
\hline & & & & \\
\hline POUPANÇA & 2014 & 2015 & 2016 & \\
\hline Valor & $-R \$ 10.000,00$ & $-R \$ 10.000,00$ & $-R \$ 10.000,00$ & \\
\hline Taxa & $6,74 \%$ & $7,61 \%$ & $7,99 \%$ & \\
\hline Período & 1 & 1 & 1 & \\
\hline Rentabilidade & $\mathrm{R} \$ 10.674,00$ & $\mathrm{R} \$ 10.761,00$ & $\mathrm{R} \$ 10.799,00$ & \\
\hline R. Liquida & $\mathrm{R} \$ 674,00$ & $\mathrm{R} \$ 761,00$ & $\mathrm{R} \$ 799,00$ & \\
\hline
\end{tabular}

Fonte: Pesquisa do Autor

A poupança teve como resultado durante 3 anos um montante acumulado de $\mathrm{R} \$ 2.234,00$ reais onde nesta aplicação o investidor não pagou imposto de renda sendo assim toda remuneração não é afetada. Conforme visto anteriormente a poupança é uma fonte de renda fixa, onde o investidor sabe exatamente o valor que será resgatado ao final do período, diferentemente da renda variável que não existe a possibilidade de se saber ao certo o montante final.

Tabela 4 - Fundo Imobiliário

\begin{tabular}{|c|c|c|c|c|}
\hline & \multirow{3}{*}{$\begin{array}{c}\text { IR } \\
\text { NDA }\end{array}$} \\
\hline & & & & \\
\hline POUPANÇA & 2014 & 2015 & 2016 & \\
\hline Valor & - $R \$ 10.000,00$ & $-\mathrm{R} \$ 10.000,00$ & $-\mathrm{R} \$ 10.000,00$ & \\
\hline Taxa & $12,70 \%$ & $13,36 \%$ & $13,89 \%$ & \\
\hline Período & 1 & 1 & 1 & \\
\hline Rentabilidade & $\mathrm{R} \$ 11.270,00$ & $\mathrm{R} \$ 11.336,00$ & $\mathrm{R} \$ 11.389,00$ & \\
\hline R. Liquida & $\mathrm{R} \$ 1.270,00$ & $\mathrm{R} \$ 1.336,00$ & $\mathrm{R} \$ 1.389,00$ & \\
\hline
\end{tabular}

Fonte: Pesquisa do Autor

O fundo imobiliário teve durante os 3 anos aplicados uma rentabilidade liquida de $R \$ 3.995,00$ gerando um ganho de $R \$ 1.161,75$ reais acima da caderneta de poupança.

O fundo imobiliário pagou seus rendimentos mensalmente sem cobrança de IR, porem o investidor paga $20 \%$ IR sobre o ganho da valorização do papel (fundo) mas o autor não considerou ganho sobre o papel, portanto cada aplicação teve seus ganhos isentos de IR. 
O fundo imobiliário é um conjunto de ativos que compõe o setor imobiliário, um conjunto de pessoas com o mesmo objetivo de alavancar seus ganhos através do mercado imobiliário.

\section{CONSIDERAÇÕES FINAIS}

No capítulo anterior foram apresentados os dados obtidos através da pesquisa do autor e com isso elaborado tabelas onde demonstraram todo o ganho possível com cada modalidade de investimento. O fundo foi totalmente viável e obteve um ganho muito maior do que a caderneta de poupança.

Se for utilizada a taxa de $10,67 \%$ (IPCA) no ano de 2015 a caderneta de poupança não teve em nenhum ano um ganho acima da inflação, mostrando a todos que todo dinheiro aplicado durante esse período teria sido corroído pela inflação.

Já por outro lado o fundo teve durante os 3 anos um ganho acima da inflação, mostrando que se torna um investimento viável para o pequeno investidor que quer aplicar em imóveis e não tem um capital expressivo.

O fundo imobiliário é um investimento de baixo capital inicial e que torna o negócio totalmente interessante e rentável ao pequeno investidor. Vale ressaltar que apesar do fundo não ter uma volatilidade tão expressiva em relação as taxas de remuneração, cabe ao investidor saber que se trata de uma aplicação de renda variável.

Como todo investimento, deve-se buscar informações a respeito da aplicação e sempre buscar a diversificação para minimizar o risco de seu dinheiro aplicado, mas os fundos de investimentos imobiliários são grandes oportunidades de investimentos para as pessoas que não possuem um alto valor financeiro e que desejam investir no setor imobiliário e com isto alavancar ainda mais seus ganhos.

\section{REFERENCIAS}

BRASIL. BANCO CENTRAL. Disponível em: <http://www4.bcb.gov.br/pec/ poupanca/poupanca.asp>. Acesso em: 20 nov. 2016.

BELO HORIZONTE. Fundo de investimento imobiliário: análise jurídica e econômica do sistema de publicidade de informações, das restrições operacionais e dos fatores de risco. 
BOVESPA. Fundo de Investimento Imobiliário (FII). Disponível em:

<http://www.bmfbovespa.com.br/pt_br/produtos/listados-a-vista-e-derivativos/rendavariavel/fundos-de-investimento-imobiliario-fii.htm>. Acesso em: 20 nov. 2016.

BRASIL. RECEITA FEDERAL. Disponível em:

<https://www.receita.fazenda.gov.br/PessoaFisica/IRPF/2006/perguntas/AplicFinanR enFixaRenVariavel.htm>. Acesso em: 25 abr. 2017.

CANALINI, Alexandre. Gestão de investimentos. 1 ed. Rio de Janeiro: Livre Expressao, 2012.

COELHO, Elizabeth Alves. Pós-graduação "lato sensu" AVM Faculdade Integrada. Diss. Universidade Candido Mendes, 2012.

CONSELHO DE VALORES MOBILIARIOS, Disponível em:

<http://www.cvm.gov.br/legislacao/inst/inst472.html>. Acesso em: 20 nov. 2016.

DALLAGNESE, Jonir. Investimentos em renda variável: o perfil do investidor dos clientes do Segmento Estilo da agência Bento Gonçalves (RS). 2007. Trabalho de Conclusão de Curso (Especialização em Gestão Financeira) - Universidade Federal do Rio Grande do Sul. Bento Gonçalves, RS, 2007.

MARTINI, Marcos Felipe Gomes. MBA Mercado de Capitais. Renda fixa versus renda variável: uma análise descritiva entre as rentabilidades dos investimentos.

Revista Especialize On-line IPOG, 2013.

MERITO DESENVOLVIMENTO IMOBILIARIO I FII. Disponível em:

$<$ http://www.meritoinvestimentos.com/fundos/investimento-imobiliario-fii/>. Acesso em 10 abr. 2017.

SCOLESE, Daniel et al. Análise de estilo de fundos imobiliários no Brasil. Revista de Contabilidade e Organizações, v. 9, n. 23, p. 24-35, 2015.

VALIM, Vinícius Ziegler. Riscos e Cuidados com Investimentos no Mercado Imobiliário. Revista Especialize On-line IPOG, v. 1, n. 6, 2013.

VEIGA, Luiz Humberto Cavalcante. Alteração no cálculo da poupança: pontos para uma discussão mais precisa. 2009. Disponível em:

<http://bd.camara.gov.br/bd/handle/bdcamara/1305> Acesso em: 25 abr. 2017.

Artigo recebido em: 27/05/2017

Artigo aprovado em: 11/08/2017 